\title{
ACC AND COMMUNITY RESPONSIBILITY
}

\author{
Garry Wilson*
}

Garry Wilson, the Chief Executive Officer of the Accident Compensation Corporation, offered these thoughts as the last presentation to the symposium

Faraway South Pacific islands. A breathtakingly beautiful alpine and coastal land - clean, green and empty. A land where rugged laconic farmers and fishermen conquer mountains and trout-filled rivers. That is one popular international image of New Zealand.

But there is another mythology. And this one has a potent influence on the way in which New Zealand's four million people actually live together. This driver is a powerful social conscience. It has created an idealistic country where reformist law-makers have long endeavoured to ensure that all citizens have an acceptable standard of living, regardless of their circumstances.

New Zealanders' social conscience has expressed itself in many forms over the years, fuelled by the strongly egalitarian values of $19^{\text {th }}$ century immigrants fleeing poverty and lack of opportunity in Ireland and Scotland and to a lesser extent England. In 1893 New Zealand became the first national State in the world to give women the right to vote in government elections. By the 1920s a welfare state existed for wage workers.

After the Great Depression, the Labour Government in 1938 passed the Social Security Act, an Act "to provide for the payment of superannuation benefits and other benefits designed to safeguard the people of New Zealand from disabilities arising from age, sickness, widowhood, orphanhood, unemployment or other exceptional circumstances; to provide a system whereby medical and hospital treatment will be made available to persons requiring such treatment; and, further, to provide such other benefits as may be necessary to maintain and promote the health and general welfare of the community."

This social welfare system has remained intact for the 66 years since then, despite political and economic changes and despite ongoing heated debate.

* Chief Executive, Accident Compensation Corporation. 
It is against this background of collective responsibility for all New Zealanders during time of need - from cradle to grave - that in 1974 the Government introduced a new system of accident compensation.

The essence of the new system was, and still is, very simple and, in world terms, revolutionary. From 1 April 1974 every New Zealand resident would have comprehensive, 24-hour, "no-fault" coverage against injury. In exchange for that coverage, New Zealanders would give up the right to sue for personal injury damages.

When the 1967 Royal Commission recommended the no-fault approach to compensation for personal injury, its chairman Sir Owen Woodhouse said: "Injury arising from accident demands an attack on three fronts. The most important is obviously prevention. Next in importance is the obligation to rehabilitate the injured. Thirdly, there is the duty to compensate them for their losses."1

To deliver the new scheme, the Government in 1974 established the Accident Compensation Commission, a name quickly and popularly shortened to ACC.

Today the scheme remains a world leader in providing cost-effective rehabilitation and compensation, and stands as a testament to the vision of Sir Owen Woodhouse. A Crown entity, ACC's performance is overseen by a Board of Directors appointed by the Minister for ACC.

ACC's overarching role remains to contribute to a nation where there are fewer injuries and where those injured return quickly to well-being.

During the 30 years ACC has existed, New Zealanders have supported the scheme's cover on the basis of community responsibility. People do not, strictly-speaking, pay for their own insurance as such but rather contribute to injury accounts which cover all members of groups with similar levels of injury or risk of injury.

The six injury accounts are:

(1) Employers': covers work-related injuries; funded from levies paid by employers;

(2) Self-Employed Work: covers all personal work-related injury to self-employed; funded by their earnings-related levies;

(3) Earners': covers non-work injuries (including home and sport); funded from earners' levies and self-employed levies based on earnings;

(4) Non-Earners': taxpayer-funded; covers all injuries to people not in the paid workforce including students, children, beneficiaries and older people;

1 Royal Commission of Inquiry into Compensation for Personal Injury in New Zealand Compensation for Personal Injury in New Zealand: Report of the Royal Commission of Inquiry (Government Printer, Wellington, 1967) para 2. 
(5) Motor Vehicle: covers all injuries involving motor vehicles on public roads; funded from petrol excise duty and a levy collected with the motor vehicle relicensing fee;

(6) Medical Misadventure: covers injuries during treatment; funded from earners' and nonearners' accounts.

Nowadays ACC touches the lives of most New Zealanders. It handles 1.6 million claims a year - roughly one in three New Zealanders.

At some stage in their lives just about every New Zealander is entitled to make a claim for their own recovery - or at the very least knows someone who is or has been "on ACC".

Most of the injuries are minor and involve the cost of a treatment visit. These claims are processed instantly. But last year 1000 people were killed accidentally and 101,600 moderately or seriously injured. A further 13,000 have ongoing claims with ACC, receiving financial assistance and rehabilitation support.

ACC's contribution to the treatment and financial compensation of the injured individual compares favourably with the state-funded health sector.

As an example, take the circumstances of two workers who earn $\$ 50,000$ a year - David has a leg amputated after a work accident at his construction site while John has bone cancer and requires a leg amputation.

Under ACC, David is entitled to receive acute hospital services, elective surgery, financial assistance of NZ\$769 a week or a lump sum of $\$ 13,000$, and a wide range of social and vocational rehabilitation for example home modifications, vehicle modifications, home help and childcare, and training programmes. David has a case manager assigned to work with him to ensure he receives the support he needs.

Under the publicly funded health system, John is entitled to acute hospital services and elective surgery. However, just when he has elective surgery is determined by funding issues and rationing and delay is common.

John's personal circumstances may be such that under the public health system he is entitled to financial assistance in the form of an invalid's benefit, family support and disability allowance. But his income level is tested to ultimately determine how much financial support, if any, he actually receives. The most he could receive would be $\$ 463$ a week, considerably less than the $\$ 769$ his injured counterpart would receive.

John may be entitled to receive the same rehabilitation support as David under ACC but this is also tested according to need and/or income. The benefits are provided according to the provider's priority ranking and are budget-capped. 
The current Minister for ACC, Hon Ruth Dyson, who is also the Minister for Disability Issues and Associate Minister of Health, has made it plain she would like to introduce elements of the ACC scheme into the public health system. Minister Dyson is keen to address the current degree of disparity in the support given to individuals who have been injured or acquired a work-related disease or condition and others with a disability not attributable to injury or occupation. I support her stand and suggest it could be achieved at a lower economic cost than most forecast.

Whether or not these major changes occur, it is clear that the satisfaction rates of ACC claimants are steadily increasing, and have now reached 84 per cent. This exceeds the satisfaction rates of, for example, most New Zealand banking institutions.

Among the many factors contributing to the rise in claimant satisfaction is ACC's commitment to delivering correct entitlements in a timely manner. Enhancement of ACC's electronic transaction systems means that 55 per cent of claims from health providers are processed electronically. Most employed claimants now receive compensation for loss of wages within seven days of their injury being assessed by a provider of treatment (down from nearly three weeks five years ago).

ACC focuses on pro-actively ensuring claimants get early, intensive treatment and early, effective rehabilitation. The majority of claims, the minor injury claims, are accepted at telephone call centres. The other moderate to serious injury claims are escalated to management by professional case managers.

As part of this commitment to early effective treatment and rehabilitation, ACC works closely with New Zealand's providers of treatment and rehabilitation. As well as funding research into best practice, ACC also funds the publication and delivery of best practice guidelines in a wide variety of media. ACC employs contracts to ensure providers deliver expected standards of care. Earlier direct access to service has reduced waiting times and halved the time the average claimant spends on ACC.

Finding out about how claimants believe they can be better informed and served is crucial for an organisation aiming to serve its community responsibly. Besides employing regular extensive independent surveys, ACC has established formal channels through groups such as the Consumer Outlook Group, Pacific Advisory Group and the Maori Advisory Group, Te Roopu Manawa Mai to exchange valuable ideas and information.

Another contributor to rising satisfaction is the Code of ACC Claimants' Rights. This code came into effect in 1993 and contains eight rights encouraging positive relationships between claimants and ACC. It sets out the responsibilities of both ACC and claimants as they work together for the claimant's recovery.

A prime concern of ACC is to make the scheme more accessible to ethnic communities that appear to be under-represented in the claims statistics. For instance, Maori, who are overrepresented in serious injury claim statistics, are under-represented in minor claims - they have 
trouble interfacing with ACC. Asian communities, too, as well as Pacific peoples and older New Zealanders make claims at a lower rate than they should. Improving customer access is now a major focus for ACC, which now has a division charged with doing just that.

If the concept of community responsibility is fundamental to the distribution of entitlements, it is also essential to their funding. The founding Woodhouse principles argued that society benefits from the outputs of its members and therefore must take responsibility for them.

Accordingly, the community should bear the costs of injury to its members and fund the costs on an equitable basis (through levies reflecting the relative injury risks).

Considerable effort goes towards setting fair levy rates each year. The levy rate for each risk group is proposed by ACC taking into account the combined effect of factors such as claim costs, interest rates, scheme expenses, reserves adjustment, and income or liable earnings. The public is invited to request consultation documents and actuarial assessment papers and make submissions on the proposed rates. The ACC Board then recommends rates to the Minister for ACC, reflecting the submissions received as part of the public consultation process, the latest claims experience, and the recent cost trends for each group of levy payers.

The Minister obtains further advice from officials and actuaries before making recommendations to Cabinet. Cabinet finalises the levy rates and once the Government has set the average rate, individual rates are finalised and incorporated into draft levy regulations. The regulations and new levy rates then come into effect.

While risk groups can always be expected to question any increase in their levy rates, ACC nevertheless takes heart that comparisons with the average levy rate in Australia are very much in New Zealand's favour. New Zealand's average workers' compensation levy rate, standardised for industry mix, is only NZ\$0.85, compared with Australia's average of $\$ 2.47$. ACC has reduced this rate by over half in the past six years - the consequence of better overall performance.

Being able to set fair levies depends too on ACC's controlling scheme expenditure and making quality investments to ensure sufficient reserves exist to cover the future costs of ongoing claims.

One of the most visible ways in which ACC discharges its responsibility to the community is in the field of injury prevention. ACC has taken a lead role in preventing injury in New Zealand - not an easy task given that New Zealanders on the whole are a fairly active group who take to the road, the water, the sports field, and the hills with gusto.

ACC's ThinkSafe campaign is seizing the public's imagination. Working closely with employers, providers, sports and recreation groups, councils and local authorities, and other government agencies, ACC is engaged in numerous initiatives to promote safety. Dynamic advertising, sometimes shocking, sometimes witty, always attention-grabbing, is aimed at the heart 
of the Kiwi culture. In addition, ACC is the lead agency in developing national strategies to prevent falls and drowning, two of six priorities in the New Zealand Injury Prevention Strategy. ${ }^{2}$ This strategy, a new Government initiative, sets out a vision of New Zealanders becoming injury free while continuing to lead active and challenging lives.

Implementing an improved IT focus has been expensive - lifting spending from $\$ 4$ million per annum to $\$ 42$ million planned this year. But the pay-back is worth it. Savings of the 10 to 20:1 order are still being achieved.

The radical ACC scheme may be 30 years old now, but thanks to its steady evolution and the advantages of digital technology, it is serving the community more efficiently and imaginatively than would have been thought possible back in 1974.

2 Hon Ruth Dyson New Zealand Injury Prevention Strategy (Accident Compensation Corporation, Wellington, 2003) 26. 